\title{
Projections of Selenga river runoff in the XXI century and uncertainty estimates
}

\author{
Tatiana Millionshchikova \\ Water Problems Institute of the Russian Academy of Sciences, Moscow, 119333, Russia \\ Correspondence: Tatiana Millionshchikova (tatyana.million@mail.ru)
}

Published: 1 August 2019

\begin{abstract}
The Selenga River, which originates in Mongolia, contributes nearly $50 \%$ of the total inflow into Lake Baikal. Since 1996, the longest low-flow period has been observed. This paper focuses on the spatially distributed process-based modeling to assess possible runoff changes under climate projections in the XXI century using an ensemble of global climate models (GCMs) from ISI-MIP2 (Inter-Sectoral Impact Model Intercomparison Project, phase 2) and RCP-scenarios (Representative Concentration Pathway) as inputs. The ECOMAG hydrological model was applied to simulate possible runoff changes in the Selenga River basin. According to the simulations, the low-flow runoff into Lake Baikal will be continued throughout the XXI century under all the RCP-scenarios. Furthermore, as hydrological projections for the future are characterized by significant climate projections uncertainty, ANOVA (analyses of variance) test was used to quantify the sources of this uncertainty. The calculations showed that the contribution of the model uncertainty (differences between GCMs) is much higher than the contribution of the scenario uncertainty (variability of RCP-scenarios) although it increases at the end of the century.
\end{abstract}

\section{Introduction}

Modern spatially distributed process-based hydrological models are increasingly applying for the analysis of the mechanisms of hydrological system responses to future climate changes. The constructed scenarios of future climate can be simulated by climate models and then used as inputs into regional hydrological models (e.g. Gelfan et al., 2015). Implementation of such models is among key problems in catchment hydrology.

The transboundary Selenga River is an important area for hydrological research a being important water and contaminant sources for Lake Baikal (Chalov et al., 2015). Location in two countries makes a process of development of a distributed process-based hydrological model rather difficult. This is due to the sparseness of observation data and the lack of information about the characteristics of the underlying surface. Here, since 1996, a significant decrease in annual runoff amount has been observed (Frolova et al., 2017), which is caused by regional climate changes (Törnqvist et al., 2014). Due to uncertainty in estimated projections inflow to Lake Baikal, the continued increase in hydro-climatic and anthro- pogenic impacts creates additional difficulties for water resources management in the region. Therefore, the problem of developing a robust hydrological model for the Selenga River basin has become especially urgent.

Most of the studies of the impact of current and future climate changes on the water regime in Selenga River basin are described only for the Mongolian part of the basin (Batima, 2006; Menzel et al., 2008; Malsy et al., 2013; Hülsmann et al., 2015). There is hydro-climatic change assessment for the entire Selenga River basin using global hydrological model (Törnqvist et al., 2014), but calculations based on global models contain considerable uncertainty (Krysanova et al., 2018), and their applicability is not obvious. The regional hydrological model for the entire Selenga River basin is presented in two recent publications (Moreido and Kalugin, 2017; Karthe et al., 2017), but the results do not allow to assess the model ability to reproduce the decreasing trend in long-term variations of observed runoff.

In last decade, there is a better agreement between the results of calculations obtained by global climate models (GCMs) and the ones obtained by regional hydrological 
models with higher resolutions (Flato et al., 2013). However, even if the GCM-based hydrological model reproduces historical hydrological data correctly, the hydrological projections in the XXI century are uncertain (Gelfan et al., 2017). One main outcome of the recent studies states that the uncertainty is caused primarily by GCMs, rather than by the hydrological modeling (see review in Joseph et al., 2018).

The thorough analysis of the main sources of uncertainty in the entire model and scenario chain is considered in a significantly smaller number of works. Recently, more studies describing the application of the analysis of variance (ANOVA) test for allocation of uncertainty sources in climate impact analysis have appeared (see, e.g. in Hattermann et al., 2018). It was shown that the largest contribution in uncertainty is related to GCMs, followed by Representative Concentration Pathway (RCP) scenarios, and the smallest uncertainty - to hydrological models.

In this study, we investigate the Selenga River runoff in the XXI century. Therefore, the aim of this study is (a) to project and analyse the hydrological response to climate projections in the XXI century using an ensemble of GCMs and RCP-scenarios for the Selenga River basin; (b) to quantify the main sources of uncertainty of the obtained assessments of the possible runoff changes of Selenga River basin.

\section{Case study}

The Selenga River is the main tributary of the Lake Baikal, contributing to $50 \%$ of its surface water inflow (Chalov et al., 2015). The vast transboundary river basin $\left(447000 \mathrm{~km}^{2}\right)$ is located in the northern part of Mongolia (approximately $64 \%$ of the basin) and in Southern Siberia (Fig. 1). Natural landscapes in these areas varies from dry steppe (upstream) to Siberian taiga (downstream). The elevation ranges from 600 to $3000 \mathrm{~m}$ a.s.l. The local climate is extremely continental. The winters are long, dry, and cold, the mean monthly temperature of January is $23.5^{\circ} \mathrm{C}$. The summers are short and relatively warm, the mean monthly temperature of July is $16^{\circ} \mathrm{C}$. The annual precipitation amount ranges between 300 and $400 \mathrm{~mm}$ over the territory. Most of precipitation falls in July and August (about $45 \%$ of the annual precipitation). Therefore, Selenga river runoff varies mostly because of variations of summer precipitation (Berezhnykh et al., 2012).

\section{Material and methods}

\subsection{Description of hydrological model}

The ECOMAG (ECOlogical Model for Applied Geophysics) is a spatially-distributed process-based hydrological model, which describing snow accumulation and melt, soil freezing and thawing, water infiltration into unfrozen and frozen soil, evapotranspiration, the thermal and water regime of soil and the overland, subsurface and channel flow with a daily time step (Motovilov et al., 1999; Motovilov, 2016).
The model accounts for measurable watershed characteristics such as surface elevation, slope, aspect, land cover and land use, soil and vegetation properties. The parameters are spatially distributed by partitioning the watershed into subbasins called elementary basins. Parameterization of the subgrid processes is described in Motovilov (2016). The model is driven by time series of daily air temperature, air humidity, and precipitation intensity.

The ECOMAG model has been applied for the Selenga River basin to assess the future impact of the regional climate change on the runoff using reanalysis dataset EWEMBI as inputs. The more detailed description of model parameters determination, results of calibration and validation against the observed data can be found in Gelfan and Millionshchikova (2018).

\subsection{The hydrological response to climate projections using an ensemble of GCMs and RCP-scenarios}

To assess the impact of climate changes on runoff in the Selenga River basin throughout the XXI century, we used the output of the GCMs from the Inter-Sectoral Impact Model Intercomparison Project Phase 2 (ISIMIP2), which operated under the RCP-scenarios.

The four RCPs, namely RCP2.6, RCP4.5, RCP6, and RCP8.5, were considered in accordance with the radiation impact level RCP in the year 2100: 2.6, 4.5, 6.0, and $8.5 \mathrm{~W} \mathrm{~m}^{-2}$, respectively (IPCC, 2013). Four GCMs were used: HadGEM2-ES, IPSL-CM5A-LR, MIROCESMCHEM, GFDL-ESM2M. The original GCMs data were interpolated to a $0.5^{\circ} \times 0.5^{\circ}$ grid and bias-corrected (to reanalysis dataset WATCH) on the continental scale. The detailed description of this procedure is given in Hempel et al. (2013).

The reliability of runoff changes projections in the XXI century is determined by the correct reproduction of the GCM-driven hydrological model of observed climate conditions and runoff. The output of the hydrological model was evaluated in terms of daily runoff data observed at the basin outlet gauging station Selenga - Kabansk (Fig. 1).

In Millionshchikova (2019) it was shown that, despite the bias correction of the GCMs data against WATCH, the biaserrors in hydrological output simulated on the basis of these data still remained. Based on four climate models at four RCP-scenarios of the future anthropogenic impacts, an ensemble of possible climate changes projections for the Selenga River basin in the XXI century was obtained with correction rates that have been determined separately for each GCM relative to the historical low-flow period (1996-2005). The correction was performed by minimizing the bias-error of GCM-driven calculations on the regional scale (Gelfan et al., 2015) compared with EWEMBI-driven calculations. The assessment of hydrological consequences under climate changes in the Selenga River basin was simulated using the constructed hydrological model, driven by corrected GCMs 


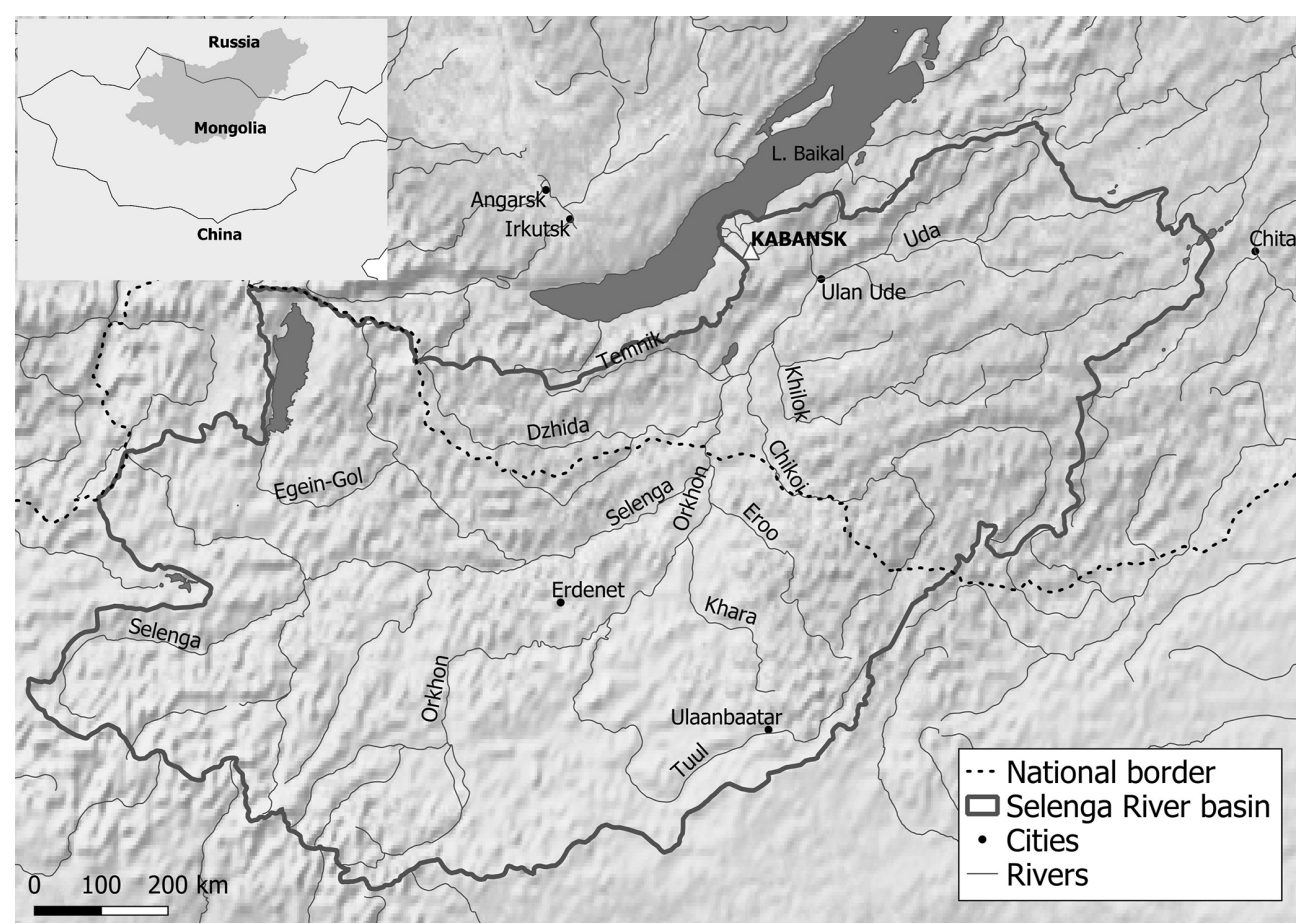

Figure 1. The Selenga River basin.

data, for three 30-year periods of the XXI century (20102039, 2040-2069 and 2070-2099). Selenga runoff anomalies, obtained by averaging runoff simulations under four GCM-based projections, were calculatated relative to the reference period (1996-2005). This allowed us to analyse differences in hydrological responses of the Selenga River basin to the specific behavior of the four RCP-scenarios.

\subsection{Quantification of runoff projections uncertainty caused by climate projections}

In this study we make use of ANOVA test given in Hattermann et al. (2018), to determine the sources of uncertainty and to express the total variation that can be attributed to the various factors. One can use different responses (in our case mean annual runoff anomaly) under climate changes to quantify sources of uncertainty and the significance of variation of the two factors: model uncertainty (differences between GCMs) and scenario uncertainty (variability of RCPscenarios):

$\mathrm{SST}=\frac{1}{N_{\mathrm{GCM}} N_{\mathrm{RCP}}} \sum_{i=1}^{N_{\mathrm{GCM}}} \sum_{j=1}^{N_{\mathrm{RCP}}}\left(Y_{i j}-\bar{Y}\right)^{2}$

where $N_{\mathrm{GCM}}$ - the number of GCMs; $N_{\mathrm{RCP}}$ - the number of RCP-scenarios; $Y_{i j}$ - is the mean annual runoff anomaly value corresponding to the climate model $i$ and $\mathrm{RCP} j$; and $\bar{Y}$ - is the overall mean of runoff anomaly corresponding to all combinations of the climate models $i$ and RCP-scenarios $j$.
SST can be further split into two main effects $\mathrm{SS}_{\mathrm{GCM}}, \mathrm{SS}_{\mathrm{RCP}}$, which are effects directly attributable to GCMs and RCPscenarios, and into interaction term $\mathrm{SS}_{\mathrm{GCM} * \mathrm{RCP}}$ :

$\mathrm{SST}=\mathrm{SS}_{\mathrm{GCM}}+\mathrm{SS}_{\mathrm{RCP}}+\mathrm{SS}_{\mathrm{GCM} * \mathrm{RCP}}$

The main effects $\mathrm{SS}_{\mathrm{GCM}}, \mathrm{SS}_{\mathrm{RCP}}$ and interaction term $\mathrm{SS}_{\mathrm{GCM} * \mathrm{RCP}}$ were calculated as:

$$
\begin{aligned}
& \mathrm{SS}_{\mathrm{GCM}}=\frac{1}{N_{\mathrm{GCM}}} \sum_{i=1}^{N_{\mathrm{GCM}}}\left(\bar{Y}_{i 0}-\bar{Y}\right)^{2}, \\
& \mathrm{SS}_{\mathrm{RCP}}=\frac{1}{N_{\mathrm{RCP}}} \sum_{j=1}^{N_{\mathrm{RCP}}}\left(\bar{Y}_{0 j}-\bar{Y}\right)^{2}, \\
& \mathrm{SS}_{\mathrm{RCP} * \mathrm{GCM}}=\frac{1}{N_{\mathrm{GCM}} N_{\mathrm{RCP}}} \sum_{i=1}^{N_{\mathrm{GCM}}} \sum_{j=1}^{N_{\mathrm{RCP}}}\left(Y_{i j}-\bar{Y}_{i 0}-\bar{Y}_{0 j}+\bar{Y}\right)^{2} .
\end{aligned}
$$

where $\bar{Y}_{i 0}$ - mean annual runoff anomaly when averaging over an ensemble of global climate models $i$ under a fixed RCP-scenario; $\bar{Y}_{0 j}$ - mean annual runoff anomaly when averaging over an ensemble of RCP-scenarios $j$ under a fixed GCM.

\section{Results}

\subsection{Selenga river runoff projections in the XXI century}

We started with pre-testing an ability of the GCM-driven regional hydrological model to simulate historical runoff in 


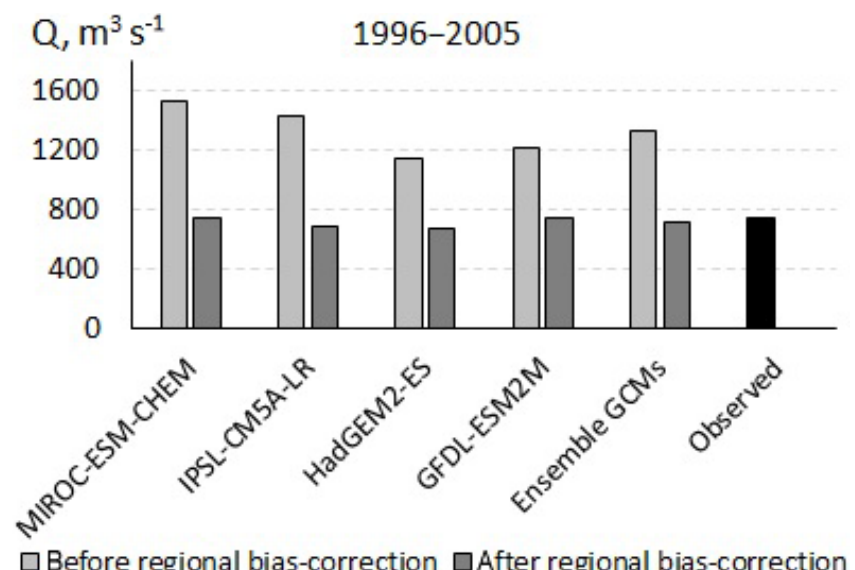

Figure 2. Results of evaluation ability of the GCM-driven regional hydrological model to simulate the observed mean annual runoff $\left(Q, \mathrm{~m}^{3} \mathrm{~s}^{-1}\right)$ in the Selenga $\mathrm{R}$. at Kabansk gage.

the Selenga River basin. According to calculations, the observed and simulated runoff data do not match (Fig. 2). The observed mean annual Selenga runoff over 1996-2005 was $741 \mathrm{~m}^{3} \mathrm{~s}^{-1}$. The relative error of the river runoff calculation by data of global climate models was $80 \%$ on average. After "regional" bias correction, the relative error of river runoff calculation by corrected data of GCMs ensemble has significantly decreased and equaled to $4 \%$ on average.

Possible changes in the climate and runoff in the XXI century under different scenarios of greenhouse gas emissions were simulated as follows. To explain the regional runoff trends for the Selenga River basin, the ensemble of climate GCMs-RCP-based projections throughout the XXI century was obtained. The ensemble-averaged trends under different RCP-scenarios were used to estimate the mean annual anomalies of air temperature $\left({ }^{\circ} \mathrm{C}\right)$ and precipitation $(\%)$ compared to the reference period (1996-2005). The estimated trends in the mean annual air temperature anomaly equals $+1^{\circ} \mathrm{C}$ per 100 years for RCP $2.6,+3{ }^{\circ} \mathrm{C}$ per 100 years for $\mathrm{RCP} 4.5,+4.2^{\circ} \mathrm{C}$ per 100 years for $\mathrm{RCP} 6.0$, and $+7.3^{\circ} \mathrm{C}$ per 100 years for RCP8.5. The estimated trends in the anomaly of the mean annual precipitation equals $+2.5 \%$ per 100 years for RCP 2.6, +8\% per 100 years for RCP 4.5, $+9 \%$ per 100 years for RCP 6.0, and $+11 \%$ per 100 years for RCP 8.5.

According to these climate projections, we simulated the possible runoff changes in the Selenga River basin. Selenga runoff anomalies are negative under all RCP scenarios and for all 30-year periods (Fig. 3). The several positive anomalies can be explained by a more significant increase of the projected evaporation simulated under the corresponding scenario. Overall, the runoff decrease will be more pronounced by the end of the XXI century. For instance, under RCP 8.5 the runoff will be decreased by $\sim 25 \%$ relative to the historical period.

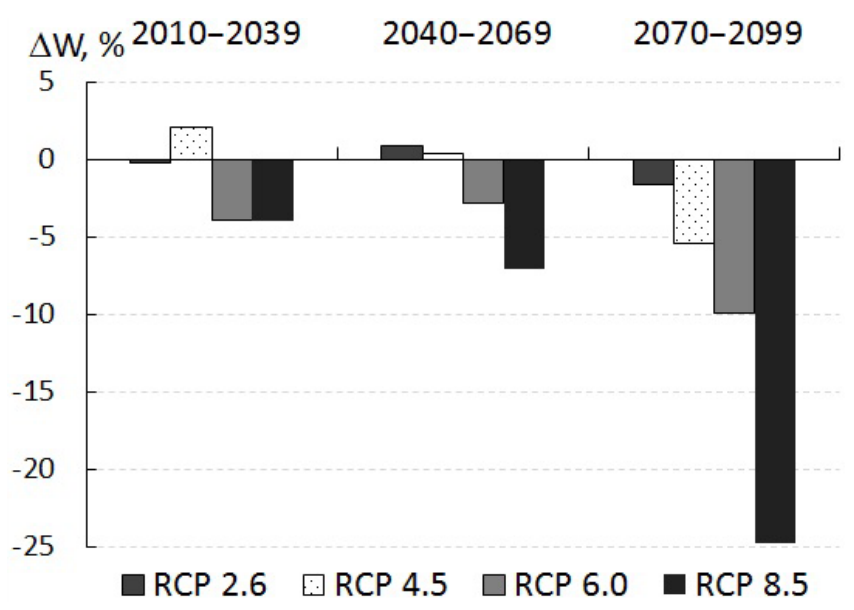

Figure 3. Mean annual runoff anomalies $(\Delta W, \%)$ obtained relative to the period 1996-2005 under the RCP-scenarios.

\subsection{Sources of uncertainty}

The projected total uncertainty in impacts (changes in runoff anomalies) for three 30-year periods until the end of the century compared to the reference period (1996-2005) is shown in Fig. 4. The results illustrate that the model uncertainty makes a significantly larger contribution into the total variance of estimated runoff anomalies than scenario uncertainty, and the latter begins to grow by the end of the XXI century. Over the period 2010-2039, the model uncertainty contribution into the total variance of estimated runoff anomalies is $58 \%$. Over the next 30-year period, (20402069) the model uncertainty contribution rises to $88 \%$ and by the end of the century (2070-2099) decreases to almost $68 \%$. Over the 2010-2039 and 2040-2069 periods the scenario uncertainty contribution into the total variance of estimated runoff anomalies is small $(2 \%)$, but by the end of the century (2070-2099) extremely grows (18\%). Over the 2010-2039 period, the contribution of the uncertainty associated with the interaction of model and scenario sources significantly exceeds the contribution of the scenario source (39\%). Whereas, by the end of the century (2070-2099) the contribution of the uncertainty associated with the interaction of model and scenario sources turns out to be comparable with scenario source $(11 \%-14 \%)$ due to a decrease in the contribution of the model source into the total variance of estimated Selenga runoff anomalies.

\section{Conclusions}

In this study, we use the regional hydrological model ECOMAG to project the possible hydrological consequences in Selenga River basin under climate change in the XXI century using data from GCMs under different scenarios of greenhouse gas emissions. The model correctly reproduces runoff over the historical period driving by the bias-corrected (to 


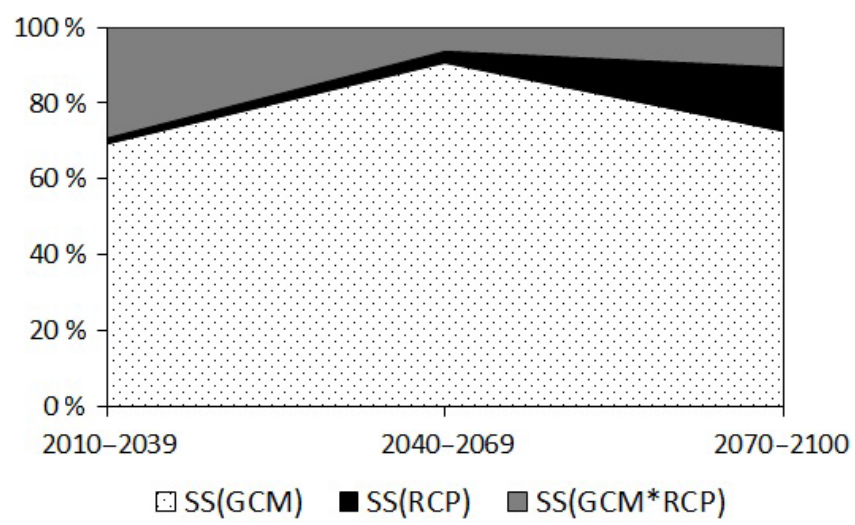

Figure 4. Sources of uncertainty in projected mean annual runoff anomalies for the Selenga River basin.

EWEMBI) climate data from selected GCMs. The obtained results provide a basis for the following assessment of hydrological model-based climate change impact for Selenga River basin. Depending on RCP-scenarios, an increase in air temperature and in precipitation equals $1-6^{\circ} \mathrm{C}$ and $3 \%-$ $12 \%$, respectively. Overall, according to these climate projections, the low-flow period into Lake Baikal will be continued throughout the XXI century under all the RCP-scenarios.

However, uncertainty in the estimated Selenga river runoff anomalies in the XXI century should be accounted. ANOVA test was used to quantify sources of runoff projections uncertainty caused by climate projections. The results showed that the model uncertainty makes a significantly larger contribution to the total variance of estimated anomalies than scenario uncertainty. Moreover, scenario uncertainty contribution into the total variance increases by the end of the XXI century. This result is expected since the uncertainty of economic and technological global development forecasts increases by the end of the century.

Data availability. The datasets generated and analyzed during the current study are available from the corresponding author on reasonable request.

Competing interests. The author declares that there is no conflict of interest.

Special issue statement. This article is part of the special issue "Land use and climate change impacts on erosion and sediment transport". It is a result of the ICCE Symposium 2018 - Climate Change Impacts on Sediment Dynamics: Measurement, Modelling and Management, Moscow, Russia, 27-31 August 2018.
Financial support. This research has been supported by the Russian Fund for Basic Research (project 17-29-05027) and State scientific assignment 0147-2019-0001 (reg. AAAA-A18118022090056-0).

\section{References}

Batima, P.: Climate Change Vulnerability and Adaptation in the Livestock Sector of Mongolia, Final Report, Project AS06, Assessments of Impacts and Adaptations to Climate Change (AIACC), International START Secretariat, Washington, DC, US, 85 pp., 2006.

Berezhnykh, T. V., Marchenko, O. Yu., Abasov, N. V., and Mordvinov, V. I.: Changes in the summertime atmospheric circulation over East Asia and formation of long-lasting low-water periods within the Selenga River Basin, Geogr. Nat. Resour., 33, 223 229, https://doi.org/10.1134/S1875372812030079, 2012.

Chalov, S. R., Jarsjo, J., Kasimov, N., Romanchenko A. O., Pietron, J., Thorslund J., and Promakhova, E. V.: Spatiotemporal variation of sediment transport in the Selenga River Basin, Mongolia and Russia, Environ. Earth Sci., 73, 663-680, https://doi.org/10.1007/s12665-014-3106-z, 2015.

Flato, G., Marotzke, J., Abiodun, B., Braconnot, P., Chou, S.C., Collins, W., Cox, P., Driouech, F., Emori, S., Eyring, V., Forest, C., Gleckler, P., Guilyardi, E., Jakob, C., Kattsov, V., Reason, C., and Rummukainen, M.: Evaluation of Climate Models, in: Climate Change 2013: The Physical Science Basis. Contribution of Working Group I to the Fifth Assessment Report of the Intergovernmental Panel on Climate Change, edited by: Stocker T. F., Qin D., Plattner, G.-K., Tignor, M., Allen, S. K., Boschung, J., Nauels, A., Xia, Y., Bex, V., and Midgley, P. M., Cambridge University Press, 741-882, 2013.

Frolova, N. L., Belyakova, P. A., Grigoriev, V. Y., Sazonov, A. A., Zotov, L. V., and Jarsjö, J.: Runoff fluctuations in the Selenga River Basin, Reg. Environ. Change., 17, 1965-1976, https://doi.org/10.1007/s10113-017-1199-0, 2017.

Gelfan, A., Semenov, V. A., Gusev, E., Motovilov, Y., Nasonova, O., Krylenko, I., and Kovalev, E.: Large-basin hydrological response to climate model outputs: uncertainty caused by internal atmospheric variability, Hydrol. Earth Syst. Sci., 19, 2737-2754, https://doi.org/10.5194/hess-19-2737-2015, 2015.

Gelfan, A., Gustafsson, D., Motovilov, Y., Arheimer, B., Kalugin, A., Krylenko, I., and Lavrenov, A.: Climate change impact on the water regime of two great Arctic rivers: modeling and uncertainty issues, Climatic Change, 141, 499-515, https://doi.org/10.1007/s10584-016-1710-5, 2017.

Gelfan, A. N. and Millionshchikova, T. D.: Validation of a Hydrological Model Intended for Impact Study: Problem Statement and Solution Example for Selenga River Basin, Water Resour., 45 (Sppl. 1), S90-S101, https://doi.org/10.1134/S0097807818050354, 2018.

Hattermann, F. F., Vetter, T., Breuer, L., Su Buda, Daggupati, P., Donnelly, C., Fekete, B., Flörke, F., Gosling, S. N., Hoffmann, P., Liersch, S., Masaki, Y., Motovilov, Y., Müller, C., Samaniego, L., Stacke, T., Wada, Y., Yang, T., and Krysnaova, V.: Sources of uncertainty in hydrological climate impact assessment: a cross-scale study, Environ. Res. Lett., 13, 015006, https://doi.org/10.1088/1748-9326/aa9938, 2018. 
Hempel, S., Frieler, K., Warszawski, L., Schewe, J., and Piontek, F.: A trend-preserving bias correction - the ISI-MIP approach, Earth Syst. Dynam., 4, 219-236, https://doi.org/10.5194/esd-4219-2013, 2013.

Hülsmann, L., Geyer, T., Schweitzer, C., Priess, J., and Karthe, D.: The effect of subarctic conditions on water resources: initial results and limitations of the SWAT model applied to the Kharaa River Basin in Northern Mongolia, Environ Earth Sci., 73, 581592, https://doi.org/10.1007/s12665-014-3173-1, 2015.

IPCC: Climate Change 2013: The Physical Science Basis. Contribution of Working Group I to the Fifth Assessment Report of the Intergovernmental Panel on Climate Change, edited by: Stocker, T. F., Qin, D., Plattner, G. K., Tignor, M., Allen, S. K., Boschung, Y, Nauels, A., Xia, Y., Bex, V., and Midgley, P. M., Cambridge University Press, Cambridge, United Kingdom and New York, NY, USA, 1535 pp., 2013.

Joseph, J., Ghosh, S., Pathak, A., and Sahai, A. K.: Hydrologic impacts of climate change: Comparisons between hydrological parameter uncertainty and climate model uncertainty, J. Hydrol., 566, 1-22, https://doi.org/10.1016/j.jhydrol.2018.08.080, 2018.

Karthe, D., Chalov, S., Moreido, V., Pashkina, M., Romanchenko, A., Batbayar, G., Kalugin, A., Westphal, K., Malsy, M., and Flörke, M.: Assessment of runoff, water and sediment quality in the Selenga River basin aided by a web-based geoservice, Water Resour., 44, 399-416, https://doi.org/10.1134/S0097807817030113, 2017.

Krysanova, V., Donnelly, C., Gelfan, A., Gerten, D., Arheimer, B., Hattermann, F., and Kundzewicz, Z. W.: How the performance of hydrological models relates to credibility of projections under climate change, Hydrolog. Sci. J., 63, 696-720, https://doi.org/10.1080/02626667.2018.1446214, 2018.

Malsy, M., aus der Beek, T., and Flörke, M.: Global change impacts on Mongolian water resources, in: Beiträge zum 44. Jahrestreffen des Arbeitskreises Hydrologie, edited by: Chifflard, P., Cyffka, B., Karthe, D., and Wetzel, K. F., Augsburg, Geographica Augustana, 95-98, 2013.
Menzel, L., Aus der Beek, T., Törnros, T., Wimmer, F., and Gomboo, D.: Hydrological impact of climate and landuse change results from the MoMo project, Int. conf, Uncertainties in water resource management: causes, technologies and consequences, edited by: Basandorj, B. and Oyunbaatar, D., Jakarta, IHP Tech. documents in hydrol, 1, 13-18, 2008.

Millionshchikova, T. D.: Selenga River Runoff Projections in the XXI Century: ECOMAG-Based Simulation Results, in: Climate Change Impacts on Hydrological Processes and Sediment Dynamics: Measurement, Modelling and Management, edited by: Chalov, S., Golosov, V., Li R., and Tsyplenkov, A., Springer Proceedings in Earth and Environmental Sciences, Springer, Cham, 61-66, https://doi.org/10.1007/978-3-030-03646-1_12, 2019.

Moreido, V. M. and Kalugin, A. S.: Assessing possible changes in Selenga $\mathrm{R}$. water regime in the XXI century based on a runoff formation model, Water Resour., 44, 390-398, https://doi.org/10.1134/S0097807817030149, 2017.

Motovilov, Y., Gottschalk, L., Engeland, K., and Rodhe, A.: Validation of a distributed hydrological model against spatial observations, Agr. Forest Meteorol., 98-99, 257-277, https://doi.org/10.1016/S0168-1923(99)00102-1, 1999.

Motovilov, Y. G.: Hydrological simulation of river basins at different spatial scales: 1. Generalization and averaging algorithms, Water Resour., 43, 429-437, https://doi.org/10.1134/S0097807816030118, 2016.

Törnqvist, R., Jarsjö, J., Pietroń, J., Bring, A., Rogberg, P., Asokan, S. M., and Destouni, G.: Evolution of the hydro-climate system in the Lake Baikal basin, J. Hydrol., 519, 1953-1962, https://doi.org/10.1016/j.jhydrol.2014.09.074, 2014. 